\title{
Brand Culture and Localization Design
}

\author{
Nan Lv \\ Visual Communication Design Department \\ Eastern International Art College \\ Zhengzhou University of Light Industry \\ Zhengzhou, China
}

\begin{abstract}
Today, in the market of product diversification, how consumers choose and buy commodity from the array of goods is the first concern of enterprise in selling product and in obtaining maximized market profits. In the modern society, with more choices, along with the increasing frequency of commodity updates, consumers also have greatly descending loyalty of goods. They often do impulse shopping. The consumers purchase behavior is very easy to be influenced by various factors. The uncertainty of consumer's consumption behavior, the way of obtaining goods and the variety of channel have become the common problem that contemporary enterprises have to face. How to attract the attention of consumers through effective marketing method and the unique brand external visual image to cause consumers find the advantages of products? How to use consumer sensibility consumption trend to get more product popularity and turn the consumer's emotion of commodity into brand loyalty? These are the priority questions related to how an enterprise creates distinct, unique, personality brand image through understanding the real needs of consumers under the influence of the experiential marketing concept. Create a story that makes a role close to life. A life body full of life experience, a person who has a story, is more likely to cause consumers' interest of exploration, more accessible to consumers in the emotional resonance. A story of the brand role is more likely to cause the consumer's association with the product.
\end{abstract}

Keywords - brand culture; localization design

\section{INTRODUCTION}

Brand image is a comprehensive reflection of the components of the brand on the mind of people, such as the impression left over by brand value, commodity attribute, brand mark, and the subjective assessment of the people, etc. No matter what it is, the brand loyalty, brand size or brand value eventually must be achieved by consumer. Consumer is the terminal. His psychological reflection of the brand fundamentally impacts consuming behavior. Therefore, confronted with the market like this, in setting up brand image, enterprises tried hard to cater to the target consumers to forge their own aesthetic orientation through brand image, to understand the consumer demand through the detailed market analysis and to satisfy the consumer's psychological need for his identity through the brand expectations and products.

\section{THE IMPORTANT ROLE OF BRAND IMAGE IN MARKETING OF THE ENTERPRISE}

From the real needs of targeted consumer groups, through the creation of a role image with unique personality characteristics and rich affinity, with a personalized and unique brand role, the enterprise could effectively distinguish it from other brands, while attracting consumers with the same personality characteristics, so that consumers understood and identified the value of the brand building, so that consumers had favor and intimacy to the brand psychologically and from social emotions to urge consumer initiative to complete consuming behavior, turning passive consumption into active one, then to cultivate consumer brand loyalty. Consumers stimulated the desire of playing consumer experience role through this unique, distinctive role image built by brand. In experiencing, he felt the product quality and quality service. This experience was acquired by consumers from the heart. Once it was set up, it was difficult to shake. For enterprises, this trust was the consumer's recognition to the brand.

Role marketing, through the establishment of a personalized, quite different image which is easy to approach, seizes the self-actualization psychological needs of consumers under the experience economy conditions, and embodies the product's intimacy through shaping the value of a virtual role, psychological and social emotional aspects, and obtains consumers favor to the brand and desire to buy, so as to realize the value of the product.

Created by people, the cartoon characters enjoy advantages that a real business image has, but also the advantages that a real "man" does not have. They are pleasing to the eye, have a sense of fun, lively, bright and clear, which other images do not have. Especially their childish lovely image and sincere temperament are a kind of incomparable intimacy. With the rapid development of animation industry and the improvement of the ability to design animation characters in China, using such concrete, naive cartoon image as a brand spokesperson, on one hand can transfer brand role longer and more stable, in more angles and areas; on the other hand, the role experience form will become the best way representing brand role under the market economy conditions. 


\section{China's Traditional Culture as a Source OF BRAND DESIGN}

In the fierce international competition, along with the development of brand internationalization and professionalization, China, as a developing country, played more and more important role in the world economic arena. As a huge potential market, China won the favor from major famous international brands. They entered the market of China to carry out their brand localization strategy to meet the aesthetic demand and cultural demand of the Chinese consumers. The Chinese enterprises gradually gained a firm foothold in the fierce international competition. They participated in not only the international competition, but also showcased internationalization and nationalization in term of brand image and brand overall competitiveness. Especially, in the completion with the international brands, the rich and unique national image of the Chinese local brands became its unique brand temperament recognized by international consumers. The traditional Chinese culture and art became the origin of the main design ideas for the local brand fresh role.

With a culture of five thousand years, China, in such a history of a long time, has generated numerous artistic languages and artistic expressions, which have laid a good technical and theoretical basis for the development of China's art. As a special form of human spiritual culture, the Chinese folk art provides a rich artistic expression language for Chinese modern art design, so we are able to feel the rich expression of the artistic modeling and artistic emotions brought by the Chinese traditional folk culture through a lot of works of modern art.

The Chinese traditional auspicious concept, in the literal creation, becomes the inspiration of artistic creation now. In China's traditional modeling concepts, the plant modeling with rich connotation, such as pomegranate, peach, finger citron, etc, passes the people's good wishes for having more children, rich life and long longevity. In the modeling of Chinese cartoon characters, the traditional ginseng baby is shaped.

In the traditional agricultural society, it was often seen that the Chinese tradition was applied to animal modeling, such as the modeling of twelve Chinese zodiac signs, which appeared in many art forms, not to speak of the dragon and phoenix patterns. They were based on the auspicious concept understanding combined with animal modeling to pass the good wished in the traditional Chinese culture for good crop weather, a golden harvest, thriving domestic animals and rich life.

\section{The Traditional CUlture ElEMENTS OF THE}

\section{BRAND DESIGN AS ONE OF ADVANTAGES IN MARKETING}

Professor $\mathrm{Wu}$ Guanying at College of Fine Arts of Tsinghua University and member of Appraisal Panel for the Asian Games mascot commented on LeYangYang like this: "The mascot has two functions, the first, to reflect the regional culture characteristics and historic characteristics of the host country or host place, at the same time, to reflect the characteristics of sports and a wide range of audience. In fact it is two connections: cultural connotation and sports. From these two points of view, LeYang Yang, first of all, has a very good name, similar to the name of the music of Guangzhou "XiYangYang". Its image is of the characteristics of Guangzhou. It is based on the five goats statues, looking very lively, in movement and in fashion, very popular. The whole image reflects the regional characteristics of Guangzhou, open and free. It is very good."

The cartoon characters established on the Chinese traditional aesthetic orientation and value concept derive from the respect to the most popular consumer aesthetic orientation to the object. Only established on the consumer's aesthetic orientation, can the cartoon roles win long-term consumer recognition, and then become the brand's most powerful spokesman.

Every person has a personality, with his own doctrine or ideas, and, due to different education and hobbies, people form their own unique behavior patterns, which is called Personal Identity. It can be said that, in addition to the name of the person, to help identify the people is their personality characteristics. The animation image's character design is not only made from the brand role character, but also is based on the local folk culture, custom culture, to shape the clear-cut image of character role with distinctive Chinese national sentiment, to get the Chinese consumer recognition emotionally and to win international consumers recognition with this role image with the Chinese emotion feature.

On the basis of emotional marketing, with the emotion to touch the people, more respect for the national sentiments of the consumers of the host country shall be paid. In the product marketing, a strong national emotional role is more likely to cause consumers emotional resonance.

The traditional Chinese culture has always advocated the realization of social and individual moral ideal. Both Confucianism and Taoism regard the pursuit of personal self perfection as the origin of the value of life. In this sense, the Chinese culture can be said to be a moral culture. In the long history of the ancient feudal society, the enlightened monarchs regarded good governance as the fundamental goal of rule. But to achieve this goal, they must take certain moral standards to govern people's thoughts, to restrict people's behavior and adjust the relationships of the society. So in the traditional culture of China, ethics is always at the core.

The ancient people thought that the fundamental difference between human beings and animal was that man had kindheartedness and a moral ethics. In his life, he should pursue ideal personality, that is, adhere to and practice ethics and ideal personality with "benevolence" as the core. The traditional Chinese culture not only attaches importance to ethics, but also advocates self -discipline, self-improvement and self perfection, so that these moral standards became the inherent requirements of individual self constraint. The Book of Rites - Learning at Higher Level makes clear the purpose from the very beginning: "What great learning teaches, is to illustrate illustrious virtue, to renovate the people, and to rest in the highest excellence." The Confucian social ideal was the praise of a noble morality, and used it to educate the public, so that people achieved the "perfection" in the moral 
realm. This is not only the program of the Learning at Higher Level, but also the program of Chinese culture. By the influence of morality above all, the Chinese people have focused on moral courage, sentiment and self-cultivation, etc, and the action played by morality in social life.

Because of the important position of family in social relations, the concept of family are deeply rooted in the hearts of Chinese people. Closely combined with this concept and adapted to it, are the ethical ideas such as loyalty, filial piety, chastity and righteousness, the religion idea such as ancestor worship, the etiquette system of worshipping the ancestors and the legal system of clan rules or family rules, and the strategy of running a state. Haier brothers expresses the Chinese brotherhood-- "Brother of same mind can break the benefits.", and the national character-- in the face of difficulties to overcome difficulties. Just by this strong national character, Haier brothers won victory in the United States and got the recognition of the American people to the Chinese brand and brand image.

The harmonious society is a concept with a strong sense of influence of the traditional Chinese idea "Harmony is precious", including father and son relation, husband and wife relation, etiquette and custom relation. These ideas are of guiding significance to the cartoon character design.

The cartoon characters such as "Hai Bao", "Fuwa" and "LeYangYang" and "Queer" created huge profits, at the same time, we see that as a marketing strategy, the cartoon characters in international events played a huge role in the improvement of the Chinese image and in creating business value, also we see the brand reputation and brand value that foreign enterprises obtained with the help of cartoon character affinity.

When the international famous brand implemented localization strategy in the Chinese market, we should realize the advantages showed by the nation attributes of brand in the fierce market competition, especially in the international strategy, the nation attribute has become the most distinctive, the most charm, and even the most attractive temperament of brand.

When we watch the Japanese style, Korean style in the Asian countries, we should focus on expressing the Chinese style of the Chinese local enterprises. The national style, national temperament and the national style is not only expressed in the color combination with Chinese characteristics, but expressed in the in-depth exploration of the nature of place of origion of product, national culture connotation and national temperament. By using the artistic expression of the nation to form its own unique personality, and then in the joint efforts of Chinese enterprises, a unique, distinctive Chinese style will be formed.

\section{CONCLUSION}

We must keep a clear mind, seriously analyze the consumption needs of targeted consumer groups, stand in the international marketing environment, use the globalization thinking combined with China's national sentiment and national culture, rationally use the Chinese traditional artistic expression language to form a brand character with a visual impact, a modern form of beauty and Chinese strong design style, so as to form an effective brand role. Then the brand role can produce a great drive in brand marketing strategy.

\section{REFERENCES}

[1] Li Yuanli The study of $r$ the cartoon image spokesman [J] News Lovers 2008: 24th

[2] Sun Wei. Cartoon image spokesman -a new way of brand endorsement [J]. Liaoning's Economy, 2008.10

[3] Gao Dingii New marketing theory: the role marketing - on "queer" marketing model [J]. Modern Enterprises, 2003.02

[4] Schultz. Integrating the marketing communications [M]. Inner Mongolia People's Press, 1997

[5] Jean Noel Kafil, Translated by Wang Jianping, Zeng Hua. Strategic brand management [M]. The Commercial Press, 2000

[6] Kleiner, Dearlove Translated by Xiang Dong How to build brand knowledge [M]. Shaanxi Normal University Press, 2003

[7] Deng Lin. Introduction to the development of the animation industry in the world [M]. Shanghai Jiao Tong University Press

[8] Lv Xuewu, Fan Zhou The forefront of the cultural and creative industries. [M]. Higher Education Press

[9] Peng Cheng. Disney Marketing Mighty 100 Years Series [M]. China Economic Publishing House, 2003.02

[10] Solomon, Lu Taihong,. Consumer behavior China Renmin University Press, 2009.07. 